\title{
SIMPLE SPECTROPHOTOMETRIC AND SPECTROFLUORIMETRIC METHODS FOR DETERMINATION OF TRIMETAZIDINE DIHYDROCHLORIDE
}

\author{
Osama H. Abdelmageed
}

Department of Analytical Chemistry, Faculty of Pharmacy, Minia University, Minia, Egypt

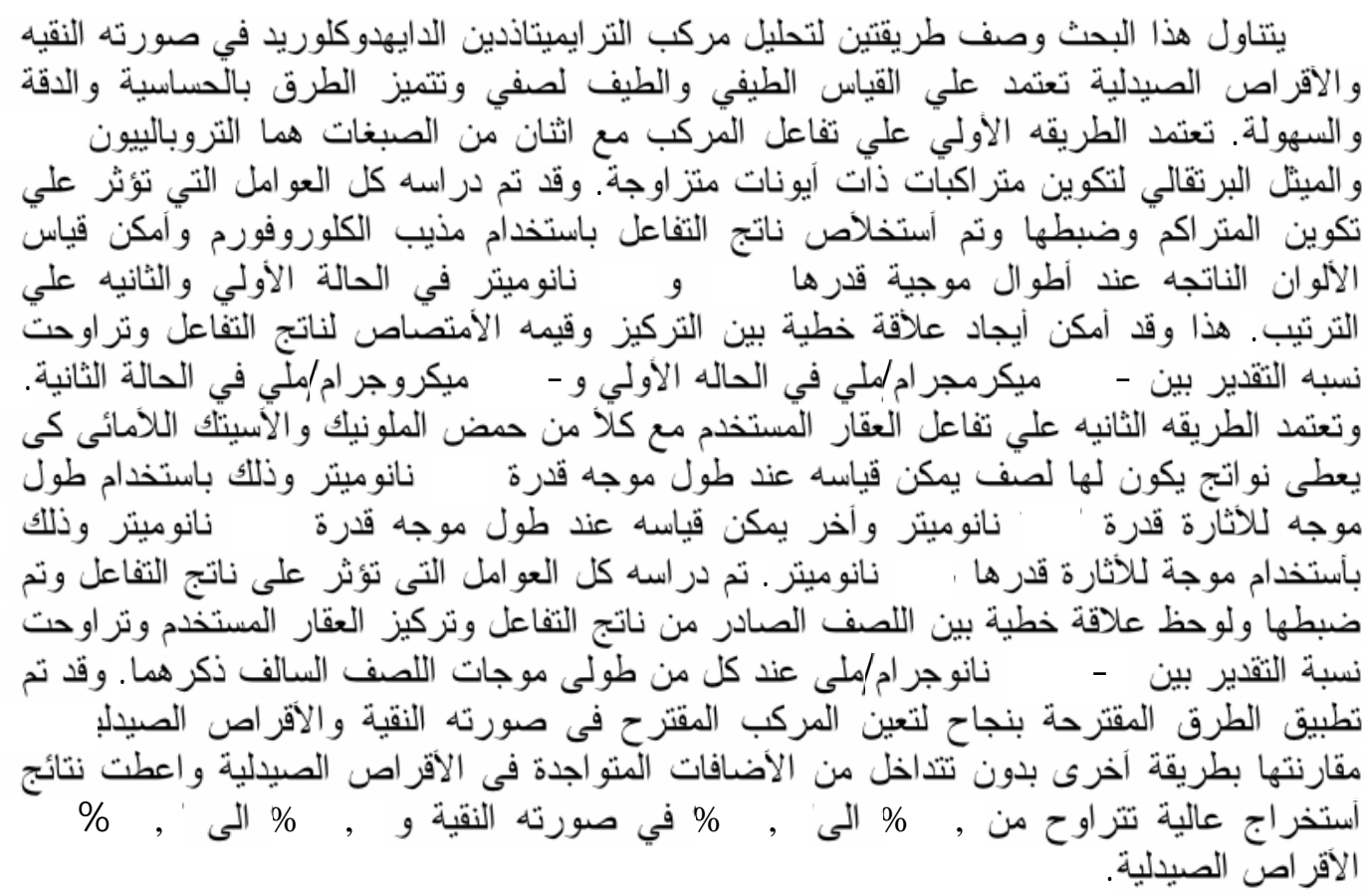

Two simple and sensitive spectrophotometric and spectrofluorimetric methods have been described for the determination of trimetazidine dihydrochloride in bulk and dosage forms. The first method depends on ion pair complexation between the cited drug with two dyes; tropaeloin 000 and methyl orange in aqueous medium. All variables affecting the formation of complex were studied and optimized. The coloured products of the drug with tropaeloin 000 and methyl orange were measured at $490 \mathrm{~nm}$ and $422 \mathrm{~nm}$ respectively, after extraction with chloroform. Beer's law was obeyed in the concentration ranges 4-20 $\mathrm{g} \mathrm{ml}^{-1}$ and 2-12 $\mu \mathrm{g} \mathrm{ml}^{-1}$ for tropaeloin 000 and methyl orange respectively. The spectrofluorimetric method depends on the condensation of malonic acid and acetic anhydride under the catalytic effect of trimetazidine dihydrochloride. The condensation product gave two emission maxima measured at $452 \mathrm{~nm}\left(\lambda_{e x}\right.$ $393 \mathrm{~nm})$ and $470 \mathrm{~nm}\left(\lambda_{e x} 428 \mathrm{~nm}\right)$. Variables affecting this condensation reaction were studied and optimized. At both maxima of emission good correlation was observed in the range 40-200 $n g \mathrm{ml}^{-1}$. The proposed methods were applied successfully for the determination of the cited drug in tablet dosage form without interference from common encountered additives. Percentage recoveries ranged from $98.9 \%$ to $99.7 \%$ in bulk and $96.9 \%$ to $98.3 \%$ in tablet dosage forms analysis.

\section{INTRODUCTION}

Trimetazidine dihydrochloride, 1-[(2,3,4Trimethoxyphenyl) methyl] piperazine dihydrochloride ${ }^{1}$ is a coronary vasodilator drug that has been used in management and prophylaxis of angina pectoris and in ischaemia 
of neurosensorial tissues as in meniere's disease. ${ }^{1}$ It seems to has an antioxidant effect. ${ }^{2}$

Several methods have been reported for the determination of Trimetazidine dihydrochloride. These methods include direct UV measurement, ${ }^{3}$ spectrophotometric methods using iodine as $\sigma$ acceptor, acetaldehyde-chloranil combination and ion pair extractive technique using bromophenol blue, ${ }^{4}$ and colorimetric determination using ferric chloride. ${ }^{5}$ Chromatographic methods were also reported; these include $\mathrm{TLC}^{6}{ }^{6}$ trace determination of drug in plasma by HPLC with fluorescence detection, ${ }^{7}$ electrochemical detection, ${ }^{8}$ GC-MS, ${ }^{9}$ and stability indicating HPTLC ${ }^{10}$ RPLC $^{11}$ assay methods. In addition, an electroanalytical method had been developed for determination of the cited drug at glassy carbon electrode using cyclic and square wave voltametry in bulk drug, tablet and urine. $^{12}$

There is no fluorimetric methods for the determination of the studied drug were found in the literature. Thus a proposed one is described which depends on the catalytic effect of the drug, as a tertiary amine derivative, on the condensation of malonic acid with acetic anhydride to give fluorescent product. In addition to this method another spectrophotometric methods based on ion pairing with two dyes: methyl orange and tropaeloin 000 and the products were extracted with chloroform and measured colorimetrically were also described. The developed methods were successfully applied for the determination of the cited drug in bulk and tablet dosage forms. The validation parameters of these methods were evaluated.

\section{EXPERIMENTAL}

\section{Chemicals and reagents}

- Analytical reagent grade chemicals and distilled water were used throughout. Trimetazidine dihydrochloride was obtained from Servier Egypt Industries Limted, 6 th October City, Guiza-A.R.E. The purity of the studied drug had been checked by a reported method $^{3}$ and was found to be 99.7\%. A stock standard solution was prepared by dissolving the drug in water to obtain $1 \mathrm{mg} \mathrm{ml}^{-1}$. It can be used without any change for a week if it is kept refrigerated and in dark through this period. Working solutions of lower concentrations must be freshly prepared by appropriate dilution of the standard solution as specified under each method followed.

- Mcllvaine buffer solution ${ }^{13}$ of $\mathrm{pH}$ ranges from 2.2-8 were prepared in freshly boiled and cooled distilled water.

- An $0.2 \% \mathrm{w} \mathrm{v}^{-1}$ methyl orange (El-Nasr Pharmaceutical Chemicals, Egypt) was prepared by dissolving the required amount of dye in distilled water.

- An 0.6\% $\mathrm{w} \mathrm{v}^{-1}$ Tropaeloin 000 (Aldrich Chemical Company; Milwaukee, WI, USA) was prepared by dissolving the required amount of dye in buffer solution of $\mathrm{pH} 5$.

- Malonic acid - acetic anhydride reagent (MAAA); was prepared by dissolving $1 \mathrm{gm}$ of malonic acid (Koch-light Lab-LTD, Colnbrook Bucks, England) in $10 \mathrm{ml}$ of acetic anhydride (El Nasr Pharmaceutical Chemical Company, Egypt) and the reagent is used within 7 hrs. ${ }^{14}$

\section{Apparatus}

UV-visible spectrophotometer (Shimadzu UV-visible 1601 PC, Kyoto, Japan) and spectrofluorimeter (Shimadzu RFI-5301 PC, Kyoto, Japan) were used for spectrophotometric and fluorimetric measurements respectively. The calibration and linearity of the last instrument were checked at frequent intervals with standard quinine sulphate $(0.01$ $\mathrm{g} \mathrm{ml}^{-1}$ ). Wavelength calibration was performed by measuring $\lambda$ excitation and $\lambda$ emission of the same standard of quinine sulphate at $\lambda_{\mathrm{ex}} 275$ and $\lambda_{\mathrm{em}} 430 \mathrm{~nm}$, although no variation in the wavelength was observed. All fluorescence measurements were recorded at the lower set sensitivity (slit width 1.5). In addition, a thermostatically controlled waterbath was used.

\section{Pharmaceutical formulations}

Vastarel tablets (Servier Egypt Industries Limited, 6 th October City, Guiza-A.R.E.) labeled to contain $20 \mathrm{mg}$ of trimetazidine dihydrochloride.

\section{Preparation of samples}

Twenty tablets were weighed and finely powdered. An amount of powdered tablets equivalent to $25 \mathrm{mg}$ was transferred into a 25 
$\mathrm{ml}$ volumetric flask with about $20 \mathrm{ml}$ distilled water. The solution was shaken well for about $10 \mathrm{~min}$ and completed to volume with distilled water. The resulting solution was filtered and the first portion of the filtrate was rejected, then the analysis is continued as explained under the general procedure.

\section{Recovery Experiments}

Add accurately weighed amount of the cited drug to an accurately weighed quantity of powered tablets, then proceed as mentioned under the analysis of tablet.

\section{General Procedures \\ Spectrophotometric methods \\ I- Using Tropaleoin 000}

An accurately measured suitable volume of the stock standard or sample tablet preparation of trimetazidine dihydrochloride was diluted with aqueous buffer of $\mathrm{pH} 5$ to obtain $100 \mathrm{~g} \mathrm{ml}^{-1}$. An aliquot of the diluted solution of the cited drug (1-5 ml) was placed into a $125 \mathrm{ml}$ separating funnel. Then $1 \mathrm{ml}$ of dye solution was added and the total volume of aqueous layer was brought to about $10 \mathrm{ml}$ with aqueous buffer of $\mathrm{pH} 5$. The solution was extracted with three successive $7 \mathrm{ml}$ quantities of chloroform and the aqueous layer was further washed with about $4 \mathrm{ml}$ chloroform. The extracts and washing solution were combined and placed into $25 \mathrm{ml}$ volumetric flask and completed to volume with chloroform. Approximately 0.1-0.2 gm of anhydrous sodium sulphate was added, shaken for about $1 \mathrm{~min}$ and filtered, rejecting the first portion of the filtrate. The absorbance of the resulting solution was measured at $490 \mathrm{~nm}$ against a reagent blank treated similarly.

\section{II- Using methyl orange}

An accurately measured suitable volume of the stock standard or sample tablet preparation of trimetazidine dihydrochloride was diluted with aqueous buffer of $\mathrm{pH} 5.6$ to obtain $100 \mathrm{~g} \mathrm{ml}^{-1}$. An aliquot of the diluted solution of the cited drug (0.5-3 ml) was placed into a $125 \mathrm{ml}$ separating funnel. Then $2 \mathrm{ml}$ of methyl orange solution was added and the total volume of aqueous layer was brought to about

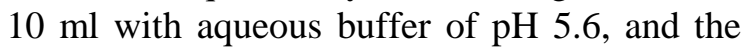
procedure was completed as under Tropaeloin
000 and the developed colour was measured at $422 \mathrm{~nm}$ against reagent blank treated similarly.

\section{Spectrofluorimetric method}

Drug aliquot of stock preparation or sample tablet preparation $(0.1-0.5 \mathrm{ml}, 1$ $\mathrm{mg} \mathrm{ml} \mathrm{m}^{-1}$ ) was transferred into a test tube, about 1-2 $\mathrm{ml}$ of ethyl alcohol was added and the resulting solution was evaporated to dryness on a boiling water bath. About $3 \mathrm{ml}$ of $10 \% \mathrm{w} \mathrm{v}^{-1}$ malonic acid acetic anhydride reagent was then pipetted and the tube was placed in a water bath at about $80^{\circ}$ for about $20 \mathrm{~min}$. The reaction mixture was cooled down to room temperature and transferred quantitatively into $25 \mathrm{ml}$ volumetric flask with ethanol and completed to volume with the same solvent. Several dilutions were made with ethanol to obtain a final concentration range from 40 to $200 \mathrm{ng} \mathrm{ml}^{-1}$. The relative fluorescence intensity was measured at $452 \mathrm{~nm}\left(\lambda_{\text {ex }} 393 \mathrm{~nm}\right)$ and at $470 \mathrm{~nm}\left(\lambda_{\mathrm{ex}} 428 \mathrm{~nm}\right)$ against reagent blank treated similarly.

\section{RESULTS AND DISCUSSION}

\section{Spectrophotometric methods}

Trimetazidine dihydrochloride is a tertiary amine salt that can be transferred from aqueous phase into organic phase in the form of an ion pair with the anionic form of the acidic dye under favourable conditions. The dyes studied for this drug were methyl orange and tropaeloin 000 . These two dyes have been used previously for determination of some pharmaceutical compounds. ${ }^{15-18}$ Their structures are shown in Scheme 1.

\section{Establishment of experimental conditions Optimum pH}

In order to establish optimum $\mathrm{pH}$ range for each dye, the drug was allowed to react with each one in aqueous solution buffered over the $\mathrm{pH}$ range 2.2-8 and the complex formed was extracted into chloroform for measurement. The absorbance of the organic layer was maximum and constant in the $\mathrm{pH}$ range 4.8-5.4 and 5.2-6.0 for tropaeloin 000 and methyl orange respectively. The absorbance is decreased out side these ranges. Hence a $\mathrm{pH} 5$ and 5.6 were used for tropaeloin 000 and methyl orange respectively. 
<smiles>CN(C)c1ccc(N=Nc2ccc(S(N)(=O)=O)cc2)cc1</smiles>

Methyl orange<smiles>O=S(=O)(O[Na])c1ccc(N=Nc2ccc(O)c3ccccc23)cc1</smiles>

Tropaeloin 000<smiles>COc1ccc(CN2CCNCC2)c(OC)c1OC</smiles>

Trimetazidine dihydrochloride

\section{Scheme 1}

\section{Effect of reagent concentration}

At $\mathrm{pH} \mathrm{5,} \mathrm{the} \mathrm{concentration} \mathrm{of} \mathrm{tropaeloin}$ 000 , prepared in the same buffer, was varied from 0.1 to $1 \% \mathrm{w} \mathrm{v}^{-1}$ using $1 \mathrm{ml}$ each time. The absorbances were found to increase steadly then remained constant when the concentration of dye within $0.4-0.8 \% \mathrm{w} \mathrm{v}^{-1}$. More than $0.8 \%$ $\mathrm{w}^{-1}$ a decrease in absorbance values were observed. Accordingly $0.6 \% \mathrm{~W} \mathrm{v}^{-1}$ concentration of tropaeloin 000 was selected. Methyl orange is not freely soluble in the used buffer solutions of different $\mathrm{pH}$. About $0.2 \% \mathrm{w} \mathrm{v}^{-1}$ aqueous solution was prepared and different volumes $(0.5-6 \mathrm{ml})$ were used for this study. At $\mathrm{pH} 5.6$, the absorbance values were found to increase with increasing volume to $1.6 \mathrm{ml}$ and then remained constant up to $3.8 \mathrm{ml}$, then start to decrease; thus $2 \mathrm{ml}$ volume was found to be optimum.

\section{Efficiency of extraction}

The efficiency of extraction procedure was studied using a fixed volume of aqueous phase and different volumes of chloroform: 10 $\mathrm{ml}, 20 \mathrm{ml}$ and $40 \mathrm{ml}$ were used in divided portions. Reproducible absorbance readings were always obtained with a total volume not less than $20 \mathrm{ml}$ chloroform, which is used throughout the extraction procedure. Shaking time of about $1 \mathrm{~min}$, after each extraction step, was found to be good enough. Other solvents such as 1,2-dichloroethane, carbon tetrachloride, toluene and benzene were tried as extracting solvent rather than chloroform with both dyes. The developed colour was not extracted by any of these solvents suggesting that the ion pair formed is soluble only in chloroform. In either cases no appreciable absorption for blank reading was observed indicated the selectivity of solvent used. Absorption spectra of the coloured products as well as their blanks, after optimization of all parameters are shown in Figures 1 and 2.

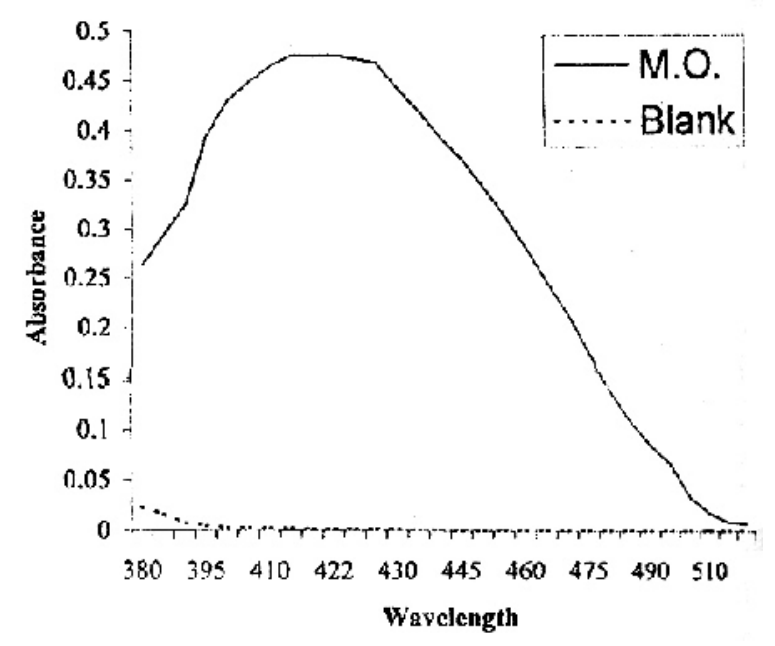

Fig. 1: Absorption spectrum of ion pair complex of the cited drug $\left(6 \mu \mathrm{g} \mathrm{ml}^{-1}\right)$ and methyl orange $\left(0.2 \% \mathrm{w} \mathrm{v}^{-1}, 2 \mathrm{ml}\right)$.

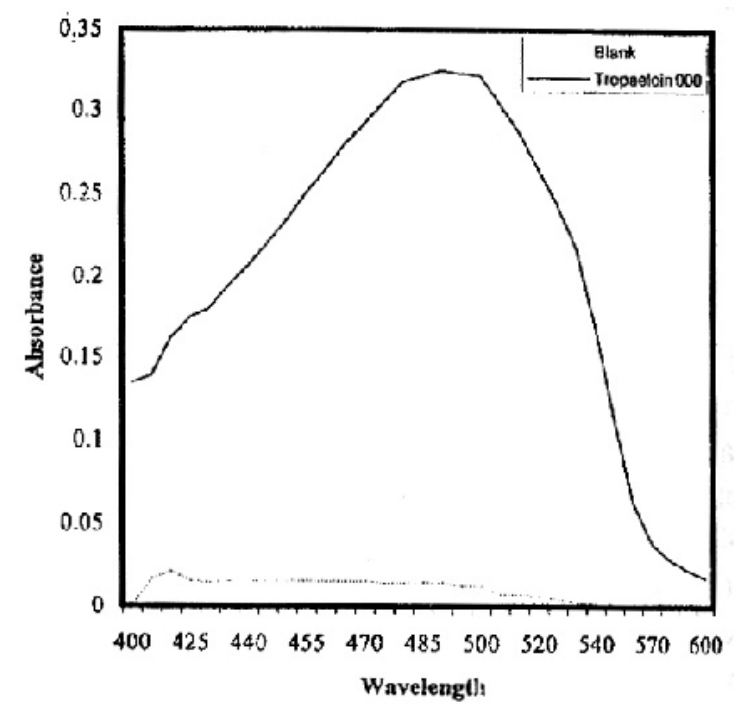

Fig. 2: Absorption spectrum of ion pair complex of the cited drug $\left(12 \mu \mathrm{g} \mathrm{ml}^{-1}\right)$ and tropaeloin $000\left(0.6 \% \mathrm{w} \mathrm{v}^{-1}, 2 \mathrm{ml}\right)$. 
The stability of the extractable coloured product was checked over a period of $1 \mathrm{hr}$. In case of tropaeloin 000 the product lost only about $2 \%$ from its original value after the time specified; where in case of methyl orange absorbance reading remained constant over the same time period. Thus measurement of colour intensity can be taken within about $10 \mathrm{~min}$. after dryness and filtration of chloroform extract.

\section{Molar ratio}

The molar ratio of ion pair complex formation between the cited drug and studied dyes were also studied through Job's method of continuous variation $^{19}$ using equimolar concentrations of both drug and dye. The stability constant were calculated as reported $^{20,21}$ and were found to be $5.37 \times 10^{10}$ and $6.46 \times 10^{11}$ for Tropaeloin 000 and methyl orange respectively. Data for this study are summarized in Table 1. According to this study the stoichiometry of ion pair complex formation was found to be 1:2; drug:dye respectively, which can be explained upon the presence of two basic centers in the drug molecule, both related to piperazine moiety and only one anionic center in each dye molecule. According to the values of the stability constants it is clear that drug : methyl orange ion pair complex is more stable than drug : tropaeloin 000 , which can be accounted on the structure difference where methyl orange molecule is less bulky relative to the other and presence of lipophillic dimethyl amino group rendered the complex more soluble in organic layer. This is proved by the poor solubility of higher concentration of methyl orange in water, thus lower concentration is used in this study relative to other dye which has polar group instead, in order to obtain comparable results. For these reasons methyl orange provide better sensitivity over tropaeloin 000 as indicated by the validation study (Table 2).

Table 1: Molar Ratios and the stability constants of the complexes formed.

\begin{tabular}{|c|c|c|c|c|}
\hline Dye & $\begin{array}{c}\text { Molar concentration } \\
\text { of dye }\end{array}$ & $\begin{array}{c}\text { Drug molar } \\
\text { concentration }\end{array}$ & $\begin{array}{c}\text { Molar ratio } \\
\text { Drug : Dye }\end{array}$ & Log K \\
\hline Tropaeloin 000 & $9.8686 \times 10^{-3}$ & $9.8686 \times 10^{-3}$ & $1: 2$ & 10.73 \\
\hline Methyl orange & $1.9000 \times 10^{-3}$ & $1.9000 \times 10^{-3}$ & $1: 2$ & 11.81 \\
\hline
\end{tabular}

Table 2: Calibration data and limits of quantification (LOQ) and detection (LOD) of trimetazidine dihydrochloride by the proposed methods.

\begin{tabular}{|l|c|c|c|c|c|c||}
\hline \multicolumn{1}{|c|}{ Method } & $\begin{array}{c}\text { Calibration } \\
\text { range } \\
\mathrm{g} \mathrm{ml}\end{array}$ \\
\hline $\begin{array}{l}\text { Tropaeloin } \\
000\end{array}$ & $\begin{array}{c}4-20 \\
\mathrm{r}=0.9990 \\
\mathrm{r}^{2}=0.9980\end{array}$ & $-0.0215 \pm 0.0129$ & $0.0294 \pm 0.0010$ & $9.16 \times 10^{3}$ & 4.39 & 1.32 \\
\hline $\begin{array}{l}\text { Methyl } \\
\text { orange }\end{array}$ & $\begin{array}{c}2-12 \\
\mathrm{r}=0.9990 \\
\mathrm{r}^{2}=0.9980\end{array}$ & $-0.0283 \pm 0.0185$ & $0.0871 \pm 0.0024$ & $27.55 \times 10^{3}$ & 2.12 & 0.64 \\
\hline $\begin{array}{l}\text { Fluorimetry } \\
393_{\mathrm{ex}} / 452_{\mathrm{em}}\end{array}$ & $\begin{array}{c}0.04-0.20 \\
\mathrm{r}=0.9990 \\
\mathrm{r}^{2}=0.9980\end{array}$ & $-0.0571 \pm 1.6643$ & $0.3414 \pm 0.0133$ & & & $\begin{array}{c}\mathrm{LOD} \\
\mathrm{g} \mathrm{ml}^{-1}\end{array}$ \\
\hline $428_{\mathrm{ex}} / 470_{\mathrm{em}}$ & $\begin{array}{c}0.04-0.20 \\
\mathrm{r}=0.9974 \\
\mathrm{r}^{2}=0.9948\end{array}$ & $-3.4571 \pm 2.6041$ & $0.4064 \pm 0.0208$ & & & \\
\hline
\end{tabular}

* average of three determinations. 


\section{Spectrofluorimetric method}

It has been reported that the reactions between polycarboxylic acids containing active methylene moieties and acetic anhydride could be catalyzed by tertiary amines to give highly coloured and fluorescent products. ${ }^{14,22-25}$ Malonic acid - acetic anhydride mixture, as an example of these mixtures, has been reported for the fluorimetric determination of some alkaloids ${ }^{14}$ and trimebtine. ${ }^{25}$ In all the previous works, ${ }^{14,22-25}$ it was suggested that malonic acid and acetic anhydride reacted together under the catalytic effect of tertiary amines to give coloured product of highly relative fluorescence intensity. The mechanism of this condensation reaction has not yet elucidated so far and a structure of the condensation product has been proposed. ${ }^{22}$ Because of the cited drug contains tertiary nitrogen, we decide to take the advantage of this reaction for its determination in bulk drug as well as in tablet dosage forms. In this work malonic acid - acetic anhydride mixture was allowed to react together using different concentrations of trimetazidine dihydrochloride as a catalyst and the product was dissolved in ethanol to give golden yellow solution with intense green fluorescence appearance. After proper dilution with ethanol the excitation and emission spectra of the product was checked out and the spectra are shown in Figure 3. It was clear that the condensation product has two excitation maxima at 393 and $428 \mathrm{~nm}$ and the emission maxima were $452 \mathrm{~nm}\left(\lambda_{\mathrm{ex}} 393\right)$ and $470 \mathrm{~nm}\left(\lambda_{\mathrm{ex}}\right.$ $428 \mathrm{~nm}$ ) respectively.

\section{Optimization of experimental conditions}

Since condensation of malonic acid - acetic anhydride should be done under completely non aqueous conditions, evaporation of the aqueous sample is done on boiling water bath after addition of ethanol to evaporate the resulting solution within short period of time.

\section{Volume of $10 \%$ w v malonic acid - acetic anhydride reagent (MAAA)}

The effect of volume of $10 \% \mathrm{w} \mathrm{v}^{-1}$ malonic acid - acetic anhydride on the relative fluorescence intensity was studied using different volumes $(0.5-4 \mathrm{ml})$ with fixed concentration of drug and condensation was carried out at $80^{\circ} .{ }^{14}$ It was observed that the relative fluorescence intensity increased with the volume of reagent reached $2 \mathrm{ml}$ then remained constant up to volume $4 \mathrm{ml}$, thus $3 \mathrm{ml}$ was selected.

\section{Water bath temperature and heating time}

Reaction was performed at different water bath temperature $\left(60^{\circ}\right.$ to boiling temp.) for a fixed period of time, $15 \mathrm{~min}$. It was clear that highest and constant relative fluorescence was observed at water bath temperature within $75^{\circ}$ to $85^{\circ}$ and decrease out this range. Thus water bath temperature at about $80^{\circ}$ was selected. At $80^{\circ}$ the effect of heating time was also studied over a period 5-30 min. Best results were obtained at about 15-25 min; thus $20 \mathrm{~min}$ was chosen. The condensation product was found to be stable over $1 \mathrm{hr}$; thus relative fluorescence intensity can be measured within this period of time.

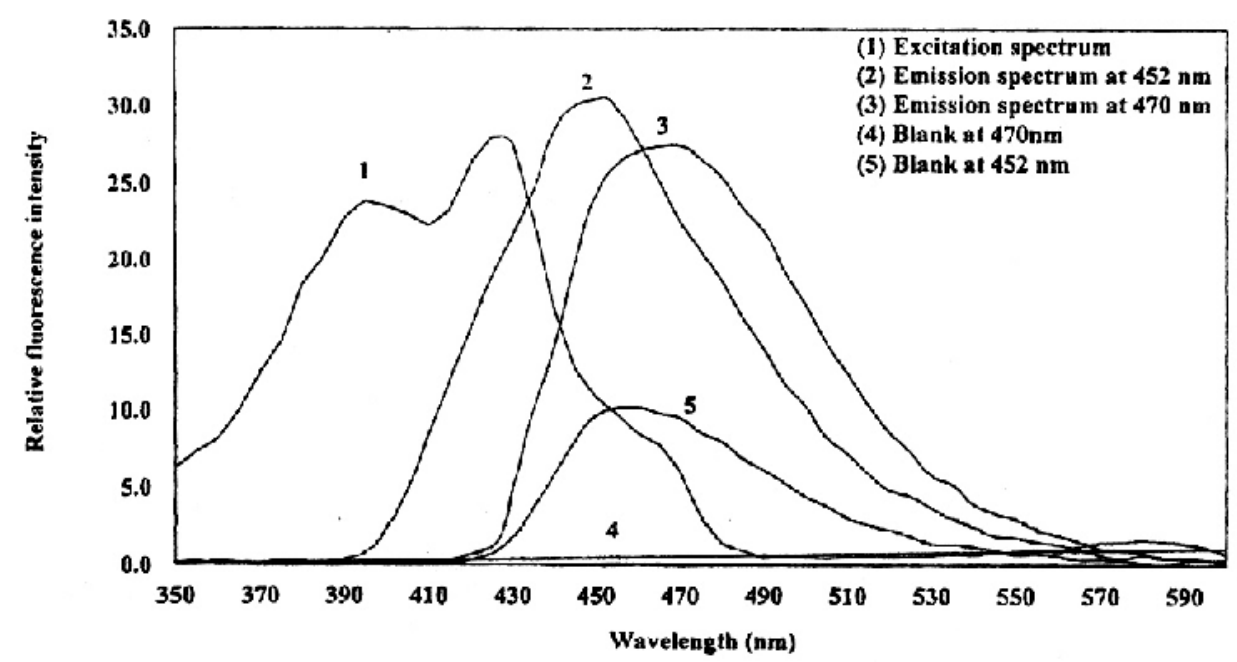

Fig. 3: Excitation spectrum ( $\lambda$ ex 393 and $428 \mathrm{~nm}$ ), emission spectra ( $\lambda$ em 452 and $470 \mathrm{~nm})$ and the blank spectra at $\lambda$ em 452 and $470 \mathrm{~nm}$ measured against pure solvent used in the determination of the condensation product of malonic acid - acetic anhydride in presence of the cited drug (65 $\mathrm{ng} \mathrm{ml}^{-1}$ final dilution). 


\section{Diluting solvent}

Different diluting solvents rather than ethanol were also studied such as acetonitrile, chloroform, dimethylformamide, methanol and water. It was clear, with the exception of chloroform where the product was immiscible, a slight change in $\lambda_{\text {ex }}$ were observed; however $\lambda_{\mathrm{em}}$ was varied depending on the solvent used. Using ethanol as diluting solvent the $\lambda_{\mathrm{ex}}$ and $\lambda_{\mathrm{em}}$ are well separated and a minimum blank reading was observed. For these two reasons ethanol was used throughout this method.

\section{Validation of the proposed methods}

\section{Linearity, detection and quantitation limits}

Using the optimal experimental conditions, absorbances increased linearly with the increase in concentration of trimetazidine dihydrochloride. The regression equations are, $\mathrm{A}=-0.0215+0.0294 \mathrm{C}$ with $\mathrm{r}=0.9990$ over the concentration range 4-20 $\mathrm{g} \mathrm{ml}^{-1}$ for drug with tropaeloin 000 and $\mathrm{A}=-0.0283+0.0871 \mathrm{C}$ with $\mathrm{r}=0.9990$ over the concentration range 2-12 $\mathrm{g}$ $\mathrm{ml}^{-1}$ for drug with methyl orange. It is clear that methyl orange dye provides better sensitivity over tropaeloin 000 , proved by the calculated molar absorptivity, however the latter is considered more selective owing to the fact that the product is measured at longer $\lambda$. Regarding the spectrofluorimetric method the regression equations are: $\mathrm{RFI}_{393 / 452}=-0.0571+0.3414 \mathrm{C}$ with $\mathrm{r}=0.9990$ over a concentration range of 40-200 ng ml ${ }^{-1}, \mathrm{RFI}_{428 / 470}=-3.4571+0.4064 \mathrm{C}$ with $\mathrm{r}=0.9974$ over a concentration range of 40-200 ng ml${ }^{-1}$. Thus RFI at $470 \mathrm{~nm}$ showed slightly better sensitivity compared with RFI at 452 nm. Detection limit (LOD) and Quantification limit (LOQ) ${ }^{26}$ were calculated as follow: $\mathrm{LOD}$ or $\mathrm{LOQ}=\mathrm{K} \cdot \mathrm{SD}_{\mathrm{a}} / \mathrm{S}$ where $\mathrm{K}=3$ for $\mathrm{LOD}$ and 10 for $\mathrm{LOQ}, \mathrm{SD}_{\mathrm{a}}$ is the standard deviation of the intercept and $S$ is the sensitivity parameter expressed by slope of the least square line. All these results are summarized in Table 2.

\section{Repeatability}

The precision of the proposed methods is checked by replicate analysis for six separate samples solution of the studied drug. The relative standard deviation (RSD) for spectrophotometric methods, using tropaeloin
000 and methyl orange were $1.58 \%, 1.29 \%$ for a concentration of $15 \mathrm{~g} \mathrm{ml}^{-1}$ and $8 \mathrm{~g} \mathrm{ml}^{-1}$ respectively. The RSD for spectrofluorimetric method were $2.53 \%$ and $1.5 \%$ for concentration of $120 \mathrm{ng} \mathrm{ml}^{-1}$ at $393 / 452 \mathrm{~nm}$ and $428 / 470 \mathrm{~nm}$ respectively. These levels of precision are suitable for the routine quality control analysis of the cited drug in bulk drug as well as in dosage forms.

\section{Accuracy and Recovery study}

The suggested methods were applied for the analysis of bulk drug and commercially available dosage form. Table 3 shows means percentage recoveries of bulk drug in the range $98.9 \% \pm 1.0$ to $99.7 \% \pm 1.6( \pm \mathrm{SD})$. Table 4 shows the percentage recoveries of the analysis of tablet dosage form in the range $96.9 \% \pm 1.1$ to $98.3 \% \pm 2.3$ of the labeled amount, indicating the concordance between experimental and nominal values. The current methods were also judged by comparing with other reported method. ${ }^{4}$ According to the variance ratio test (F-test) and t-test ${ }^{27}$ there is no significant difference between the proposed and reported methods. The accuracy of the proposed methods were also confirmed through recovery studies using standard addition method. ${ }^{28}$ Results obtained indicate good recoveries $(98.8 \% \pm 1.8$ to $99.3 \% \pm 1.3)$ and confirm absence of interferences from frequently encountered common excepients and additives (Table 4), thus the proposed methods can be considered specific.

\section{Robustness $^{29}$}

It was examined by evaluating the influence of small variation of experimental conditions such as percentage concentration or volume of dyes, $\mathrm{pH}$ of extraction for spectrophotometric method and volume of malonic acid-acetic anhydride mixture, heating time and water bath temperature for spectrofluorimetric method. It is clear from this study that none of these variable significantly affected the absorbance readings or the relative fluorescence intensity, which indicate the reliability of the proposed methods during normal usage, therefore it can be considered robust. 
Table 3: Determination of trimetazidine dihydrrochloride in bulk drug by the proposed and reported methods.

\begin{tabular}{||c|c|c|c|c|c|}
\hline \multirow{2}{*}{$\begin{array}{c}\text { Amount } \\
\text { taken mg }\end{array}$} & \multicolumn{5}{|c|}{ Recovery \%* } \\
\cline { 2 - 6 } & Tropaeloin 000 & $\begin{array}{c}\text { Methyl } \\
\text { orange }\end{array}$ & $\begin{array}{c}\text { RFI } \\
393 / 452\end{array}$ & $\begin{array}{c}\text { RFI } \\
428 / 470\end{array}$ & $\begin{array}{c}\text { Reported } \\
\text { method** }^{* *}\end{array}$ \\
\hline 25 & 98.9 & 99.9 & 102.1 & 100.8 & 98.2 \\
\hline 50 & 100.4 & 99.6 & 99.6 & 96.9 & 98.1 \\
\hline 75 & 98.2 & 98.3 & 100.2 & 98.6 & 96.5 \\
\hline 100 & 97.7 & 99.2 & 97.8 & 99.6 & 99.7 \\
\hline 150 & 99.2 & 101.2 & 98.8 & 99.3 & 100.0 \\
\hline Mean & 98.9 & 99.6 & 99.7 & 99.0 & 98.5 \\
\hline RSD & 1.0 & 1.1 & 1.6 & 1.4 & 1.4 \\
\hline
\end{tabular}

* Average of 3 determinations.

** Reference 4 using bromophenol blue through ion pair extraction method.

Table 4: Determination of trimetazidine dihydrochloride in Vastarel tablet dosage form by the proposed and reported methods.

\begin{tabular}{|c|c|c|c|c|c||}
\hline \hline $\begin{array}{c}\text { Amount } \\
\text { studied }\end{array}$ & \multicolumn{5}{|c|}{ Recovery \%* } \\
\cline { 2 - 6 } & Tropaeloin 000 & $\begin{array}{c}\text { Methyl } \\
\text { orange }\end{array}$ & $\begin{array}{c}\text { RFI } \\
393 / 452\end{array}$ & $\begin{array}{c}\text { RFI } \\
428 / 470\end{array}$ & $\begin{array}{c}\text { Reported } \\
\text { method }^{* *}\end{array}$ \\
\hline $\begin{array}{c}\text { Label claim } \\
\text { 20 mg per } \\
\text { tablet }\end{array}$ & $96.9 \pm 1.1$ & $97.5 \pm 1.5$ & $98.3 \pm 2.3$ & $97.4 \pm 1.4$ & $97.2 \pm 1.4$ \\
\hline $\begin{array}{c}\text { Amount added } \\
25 \mathrm{mg}\end{array}$ & $\mathrm{T}=0.40$ & $\mathrm{~F}=1.13$ & $\mathrm{~F}=2.71$ & $\mathrm{~F}=1.06$ & \\
$\mathrm{t}=0.33$ & $\mathrm{t}=0.91$ & $\mathrm{t}=0.10$ & \\
\hline
\end{tabular}

*Average of 5 determination

**Reference 4 using bromophenol blue through ion pair extraction method

Theoretical values of $\mathrm{F}$ and $\mathrm{t}$ at $95 \%$ confidence limit are 6.59 and 1.86 respectively.

\section{Conclusion}

The proposed methods are simple, sensitive, inexpensive and suitable for the routine analysis of the cited drug in bulk and in tablet dosage forms. The lower detection limit calculated for fluroimetric method may suggest its possible application for the determination of the cited drug in urine as well as in other biological fluids. In addition the spectrofluorimetric method is considered specific for tertiary amine because primary and secondary amines did not interfere. ${ }^{14,22-25}$ Therefore it may be suitable for the possible determination of the cited drug in presence of primary or secondary amines or its degradation products resulted from N-dealkylation where the product is expected to be piperizine and benzyl alcohol derivative.

\section{REFERENCES}

1- K. Parfitt, "Martindale, The complete Drug Reference", $32^{\text {nd }}, \quad$ Ed., Pharmaceutical Press, UK, 1999, p. 959.

2- F. Girgin, O. Karaoglu, M. Erkus, S. Tuzun, O. Ozutemiz, C. Dincer, Y. Batur and T. Tanyalcin, J. Toxicol. Environ. Health A., 59, 641 (2000).

3- A. C. Moffat (Ed.), "Clarke's Isolation and Identification of Drugs in Pharmaceuticals", Body Fluids and Post. Mortem Materials, $2^{\text {nd }}$ Ed., Pharmaceutical Press, UK, 1986, p. 1048.

4- S. A. Hussein, Alex. J. Pharm. Sci., 16, 39 (2002).

5- F. M. Abou-Attia, Y. M. Issa, F. M. Abdel Gawad and S. M. Abdel-Hamid, Farmaco., 58, 573 (2003). 
6- S.-I. Natio, S. Osumi, K. Sekisshiro and M. Hirose, Chem. Pharm. Bull., 20, 682 (1972).

7- S. Courte and N. Bromet, J. Chromatogr. Biomed. Appl., 224, 162 (1981).

8- V. R. Bari, U. J. Dhorda and M. Sundaresan, Indian Drugs, 36, 289 (1999).

9- L. Fay, G. Michel, P. Goupit, C. Harpey and M. Prost, J. Chromatogr. Biomed. Appl., 490, 198 (1989).

10- O. S. Thoppil, R. M. Cardoza and P. D. Amin, J. Pharm. Biomed. Anal., 25, 15 (2001).

11- O. S. Thoppil and P. D. Amin, J. Pharm. Biomed. Anal., 25, 191 (2001).

12- M. M. Ghoneim, P. Y. Khashaba and A. M. Beltagi, J. Parm. Biomed. Anal., 1, 235 (2002).

13- M. Pesez and J. Bartos (eds), "Colorimetric and Fluorimetric Analysis of Organic Compounds and Drugs", Marcel Dekker, Inc, New York, 1974, p. 628.

14- A. D. Thomas, Talanta, 22, 865 (1975).

15- M. H. Barary and A. M. Wahbi, Drug development and Industrial Pharmacy, 17, 457 (1991).

16- O. H. Abdelmageed and P. Khashaba, Talanta, 40, 1289 (1993).

17- T. P-Ruiz, C. M.-Lozano, A. Sanz and C. Alonso, Talanta, 41, 1523 (1994).

18- C. S. P. Sastry, K. Rao and D. S. Prasad, Talanta, 42, 311 (1995).
19- T. Rose, "Advanced Physico-Chemical Experiments", Pitman, London, England, 1964, p. 54.

20- D. T. Sawyer, W. R. Heineman and J. M. Beebe, "Chemistry Experiments for Instrumental method", John Willey \& Sons, Inc., USA, 1984, p. 205.

21- S. K. El-Khateeb, S. A. Abdelrazek and M. M. Amer, J. Pharm. Biomed. Anal., 17, 829 (1998).

22- A. R. Groth and G. Wallerberg, Acta Chem. Scand., 20, 2628 (1966).

23- A. D. Thomas, J. Pharm. Pharmacology, 28, 838 (1976).

24- A. M. Taha, S. R. El. Shabouri and A. I. Rageh, Egypt. J. Pharm. Sci., 21, 363 (1980).

25- H. M. Abdel-Wadood, Bull. Pharm. Sci., Assiut University, 25, 137, (2002).

26- J. N. Miller, Analyst, 116, 3 (1991).

27- G. H. Jeffery, J. Bassett, J. Mendham and R.C. Denny, "Vogel's Textbook of Quantitative Chemical Analysis", 5 ${ }^{\text {th }}$ Ed., The Bath Press, Great Britain, 1989, pp 140-141.

28- G. W. Ewing, "Instrumental methods of Chemical Analysis", $5^{\text {th }}$ Ed., LippincottRaven, Philadelphia, PA, 1995, pp. 484486.

29- The United Stated Pharmacopoeia, The National Formularly, USP 24, NF 19, USP Convention Inc., 12601 Twinbrook Parkway, Rochville MD, 2000, pp. 21512152. 